\title{
IDENTIFIKASI LITOLOGI BATUAN MENGGUNAKAN METODE GEOLISTRIK DENGAN KONFIGURASI WENNER PADA AREA PEMBANGUNAN KAMPUS 2 UIN SUNAN GUNUNG DJATI BANDUNG
}

\author{
Rena Denya Agustina ${ }^{*}$, Haekal Pazha ${ }^{2}$, Reva Wiratama², \\ Muhammad Minan Chusni ${ }^{1}$ \\ ${ }^{1}$ Program Studi Pendidikan Fisika, UIN Sunan Gunung Djati Bandung \\ ${ }^{2}$ Jurusan Fisika, UIN Sunan Gunung Djati Bandung \\ Email: renadenya@uinsgd.ac.id
}

Diterima: 12 Juli 2021. Direvisi: 16 September 2021 Disetujui: 30 September 2021.

\begin{abstract}
Abstrak
Penelitian ini bertujuan untuk mengidentifikasi struktur litologi batuan. Metode yang digunakan untuk menentukan jenis batuan tertentu adalah dengan menggunakan metode electrical resistivitymeter dengan konfigurasi werner, mekanisme dari metode ini adalah dengan menginjeksikan arus ke bumi sehingga akan didapat beda potensial yang dihasilkan dari respon batuan terhadap arus, kemudian akan dibaca kemudian diidentifikasi oleh nilai resistivitasnya. Variasi jenis batuan akan terlihat sesuai dengan nilai tahanan jenisnya. Penelitian ini berlokasi di areal pembangunan kampus 2 UIN Sunan Gunung Djati Bandung dan menurut lembar peta geologi regional Bandung dan sekitarnya berada pada formasi batuan QI (sedimen danau). Lintasan pengukuran geolistrik memiliki tiga jalur yaitu L.1, L.2, dan L.3 dan menggunakan 32 elektroda untuk setiap lintasan dengan jarak awal 6 meter, sehingga panjang lintasan adalah 192 meter untuk setiap lintasan. Nilai kesalahan inversi untuk L.1, L.2 dan L.3 masing-masing adalah 9,3\%, 7,2\% dan $6,1 \%$. Berdasarkan pengukuran, ditemukan litologi lokasi penelitian untuk tiga lintasan (L.1, L.2, dan L.3) yang tersusun dari lempung tufaan dengan jenis resistivitas di bawah $100 \mathrm{~m}$, tufan batupasir dengan nilai resistivitas antara 100 sampai $600 \mathrm{~m}$, dan batugamping dengan nilai resistivitas di atas $600 \Omega \mathrm{m}$.
\end{abstract}

Kata Kunci: Litologi batuan, Geolistrik, tahanan jenis, dan Wenner.

\begin{abstract}
This research has the aims to identify the structural rock litology. The method used to determine certain rock types is to use the electrical resistivitymeter method with a Werner configuration, the mechanism of this method is to inject current into the earth so that the potential difference resulting from the response of the rock to the current will be read and then identified by the resistivity value. The variations in rock types will be seen according to the value of resistance type. This research is located in the construction area of campus 2 of Sunan Gunung Djati UIN Bandung and according to the regional geological map sheet Bandung and its surroundings are in rock formations QI (lake sediment). The trajectory of geoelectrical measurement have three line, those are L.1, L.2, and L.3 and use 32 electrodes for each track with an initial spacing of 6 meters, so that the track length is 192 meters for each track. The inversion error values for L.1, L.2 and L.3 are 9.3\%,
\end{abstract}


Agustina., Pazha., Wiratama., Chusni. - Identifikasi Litologi Batuan ...

$7.2 \%$ and $6.1 \%$ respectively. Based on the measurements, the lithology of the study site was found for three trajectories (L.1, L.2, and L.3) which are composed of tuffaceous clay with resistivity types below $100 \Omega \mathrm{m}$, tufan sandstones with resistivity values between 100 to $600 \Omega \mathrm{m}$, and limestone with resistivity values above $600 \Omega m$.

Keywords: Rock lithology, Geoelectric, type resistances, and Wenner.

\section{PENDAHULUAN}

Identifikasi litologi batuan merupakan kajian yang menggabungkan dua disiplin ilmu, yaitu geofisika dan geologi. Disiplin geofisika berperan dalam memperkirakan bentuk dan sebaran lapisan batuan pada daerah yang bersangkutan sedangkan disiplin ilmu geologi berperan penting dalam hal validasi data geologi daerah yang diteliti (Arifin, 2012; Bowles \& Hainim, 1984).

Salah satu metode geofisika yang dapat digunakan untuk mengidentifikasi litologi batuan adalah metode geolistrik tahanan jenis. Jenis metode tahanan geolistrik dengan konfigurasi Wenner merupakan salah satu metode geolistrik yang dilakukan dengan cara menginjeksikan arus searah (DC) ke dalam bumi agar tegangan yang terbaca dapat diidentifikasi sesuai dengan variasi nilai resistivitas batuan/tahanan arus (Hendrajaya \& Arif, 1990; Mohammed et al., 2007).

Jenis metode resistivitas geolistrik didasarkan pada asumsi bahwa bumi memiliki sifat isotropik yang homogen. Dengan asumsi ini, resistansi tipe yang diukur adalah resistansi tipe sebenarnya dan tidak tergantung pada jarak elektroda. Namun pada kenyataannya bumi tersusun atas lapisan-lapisan dengan jenis nilai resistivitas yang berbedabeda, sehingga potensial yang terukur merupakan pengaruh dari lapisanlapisan tersebut. Dengan demikian, harga tahanan tipe yang diukur dari observasi lapangan adalah harga tahanan jenis satu lapis saja atau bisa disebut tahanan tipe kuasi (Bhattacharya, 2012; Khalil, 2006; Lashkaripour, 2003).

Besarnya jenis tahanan yang $\operatorname{tampak}\left(\rho_{a}\right)$.

$$
\rho_{a}=\frac{2 \pi}{\left[\left(\frac{1}{r_{1}}-\frac{1}{r_{2}}\right)-\left(\frac{1}{r_{1}}-\frac{1}{r_{2}}\right)\right]} \frac{\Delta V}{I}
$$


Agustina., Pazha., Wiratama., Chusni. - Identifikasi Litologi Batuan ...

atau

$$
\rho_{a}=K \frac{\Delta V}{I}
$$

dengan

$$
K=\frac{2 \pi}{\left[\left(\frac{1}{r_{1}}-\frac{1}{r_{2}}\right)-\left(\frac{1}{r_{3}}-\frac{1}{r_{4}}\right)\right]}
$$

dengan $\rho_{a}$ merupakan relativitas semu $(\Omega \mathrm{m}), \Delta V$ merupakan potensial tanah yang terukur $(\mathrm{mV}), I$ merupakan arus yang ditembakan ke dalam tanah, sedangkan $K$ merupakan faktor geometris (Loke, 1999).

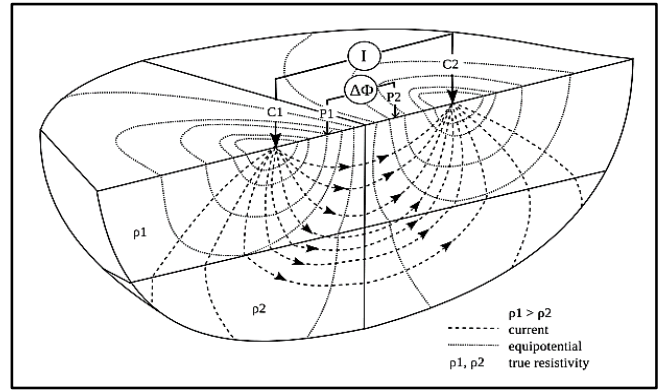

Gambar 1. Pola persebaran arah arus dalam medium homogen entropik (Knödel et al., 2013)

Konfigurasi Wenner merupakan salah satu konfigurasi yang sering digunakan dalam eksplorasi geolistrik dengan pengaturan jarak yang sama panjangn $r_{1}=r_{2}=r_{3}=r_{4}$.

Konfigurasi Wenner digunakan karena memiliki kepekaan yang tinggi terhadap perubahan vertikal, hal ini sangat penting dalam menentukan lapisan batas sebagai salah satu proses identifikasi litologi batuan di lokasi penelitian (Hendrajaya \& Arif, 1990; Syamsuddin, 2007). Dalam akuisisi data lapangan, Susunan elektroda arus dan potensial diletakkan secara simetris dengan titik sounding (titik tengah). Pada konfigurasi Wenner, jarak antara elektroda arus (C) dan elektroda potensial (P1 dan P2) sama seperti yang ditunjukkan pada Gambar 2 (Wahyono et al., 2013; Wijaya, 2015).

Berdasarkan Gambar 2, jarak AM = $\mathrm{NB}=a$ dan jarak $\mathrm{AN}=\mathrm{MB}=2 a$, dan dengan menggunakan persamaan $K$ sebelumnya makan diperoleh fungsi sebagai berikut (Reynolds, 2011; Viridi \& Hilfan, 1995):

$$
K=\frac{2 \pi}{\left[\left(\frac{1}{r_{1}}-\frac{1}{r_{2}}\right)-\left(\frac{1}{r_{3}}-\frac{1}{r_{4}}\right)\right]}
$$

$K=2 \pi a$ 
Agustina., Pazha., Wiratama., Chusni. - Identifikasi Litologi Batuan ...

sehingga faktor geometri $K$ untuk Lokasi penelitian termasuk dalam konfigurasi Wenner yang diperoleh wilayah geologi regional Bandung adalah: seperti terdapat dalam Gambar 3.

$\rho_{\omega}=K_{w} R$

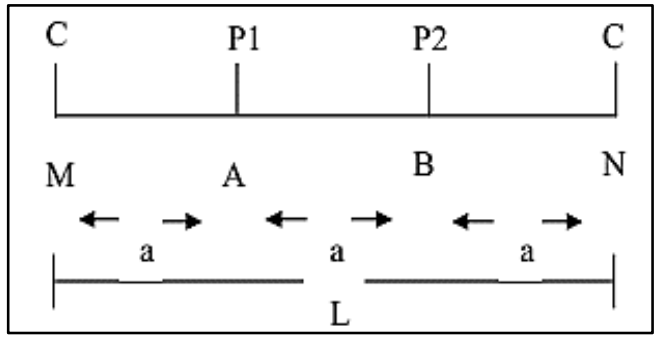

Gambar 2. Pengaturan Konfirguasi Wenner

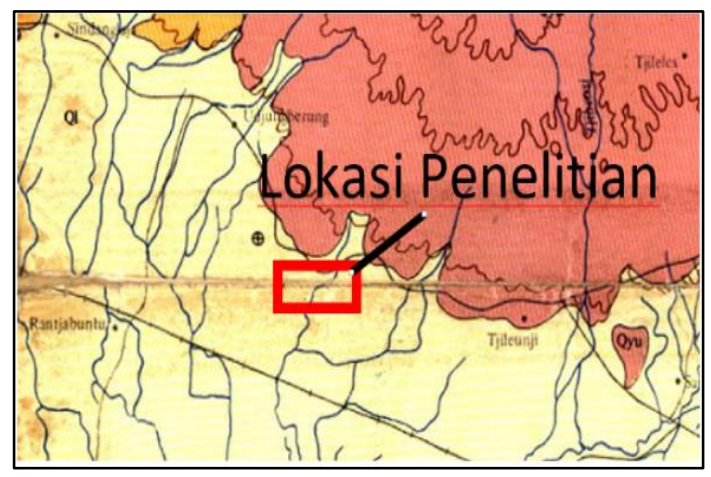

Gambar 3. Wilayah Geologi Bandung (Directorate of Geology, 1972).

Dengan informasi satuan batuan QI (sedimen danau) yang teridentifikasi dari kedalaman 0 - 125 meter, yang terdiri dari lempung tufaan, batupasir tufaan, kerikil tufaan, membentuk bidang bidang mendatar di beberapa tempat, mengandung konkresi batugamping, sisa tumbuhan, moluska air tawar dan tulang hewan vertebrata, ditemukan beberapa sisipan breksi (Silitonga, 1972)

\section{METODE}

Penelitian ini dilakukan di area pembangunan Kampus 2 UIN Sunan Gunung Djati Bandung yang terletak di Jalan Cimencrang Kota Bandung. Jumlah jalur pengukuran adalah 3 jalur (L.1, L.2, dan L.3) dan menggunakan meteran Masagi Multichannel Resistivity dalam proses akuisisi data, dengan jumlah elektroda sebanyak 32 dan jarak awal antara elektroda adalah 6-meter 
Agustina., Pazha., Wiratama., Chusni. - Identifikasi Litologi Batuan ...

sehingga setiap lintasan pengukuran memiliki panjang \pm 192 meter. Lokasi Pengumpulan dan skema pengukuran dapat dilihat pada Gambar 4.

Metode pengukuran geolistrik yang diterapkan dalam penelitian ini adalah pencitraan geolistrik menggunakan konfigurasi Wenner untuk mengidentifikasi struktur litologi batuan lokasi penelitian yang selanjutnya akan diinterpretasikan menjadi penampang geologi.

Hasil penampang geologi 2D hasil pembacaan nilai resistivitas batuan lokasi penelitian dari 3 lintasan akan diinterpolasi ke dalam bentuk penampang geologi 3D untuk memudahkan proses identifikasi litologi batuan di lokasi penelitian.

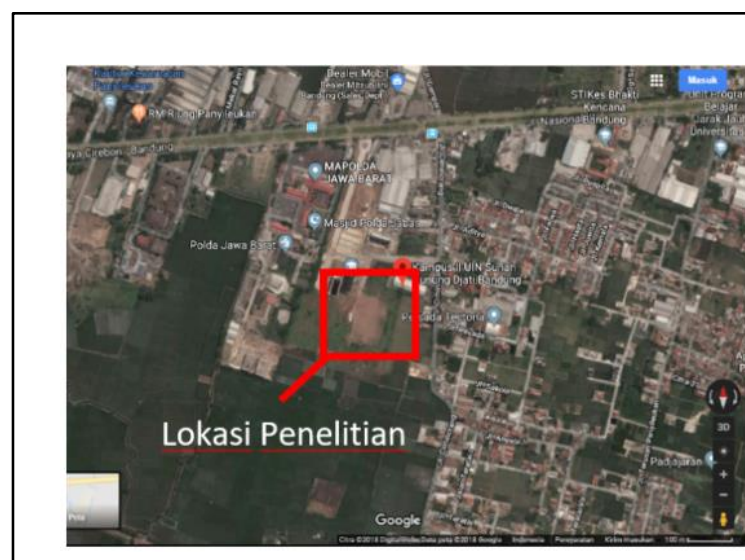

(a)

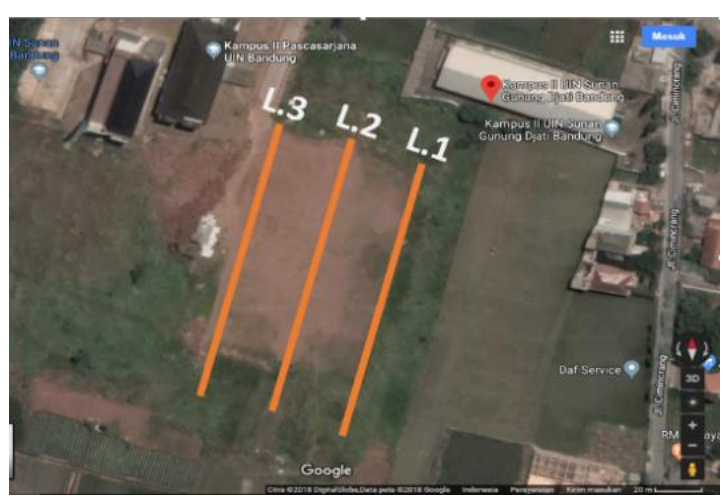

(b)

Gambar 4. (a) Lokasi Pengumpulan Data; (b) Skema Lintasan Pengukuran

(Google.inc, 2018)

\section{HASIL DAN PEMBAHASAN}

Dari pengukuran yang telah dilakukan pada ketiga lintasan lokasi penelitian didapatkan nilai kesalahan inversi untuk lintasan satu (L.1) sebesar 9,3\%, lintasan kedua (L.2) sebesar 7,2\% dan lintasan ketiga (L.3) sebesar $6,1 \%$.

Sedangkan hasil penampang 2D hasil pemodelan resistivitas dan pemodelan geologi lokasi penelitian dapat dilihat pada Gambar 5, Gambar 6, dan Gambar 7. 
Agustina., Pazha., Wiratama., Chusni. - Identifikasi Litologi Batuan ...

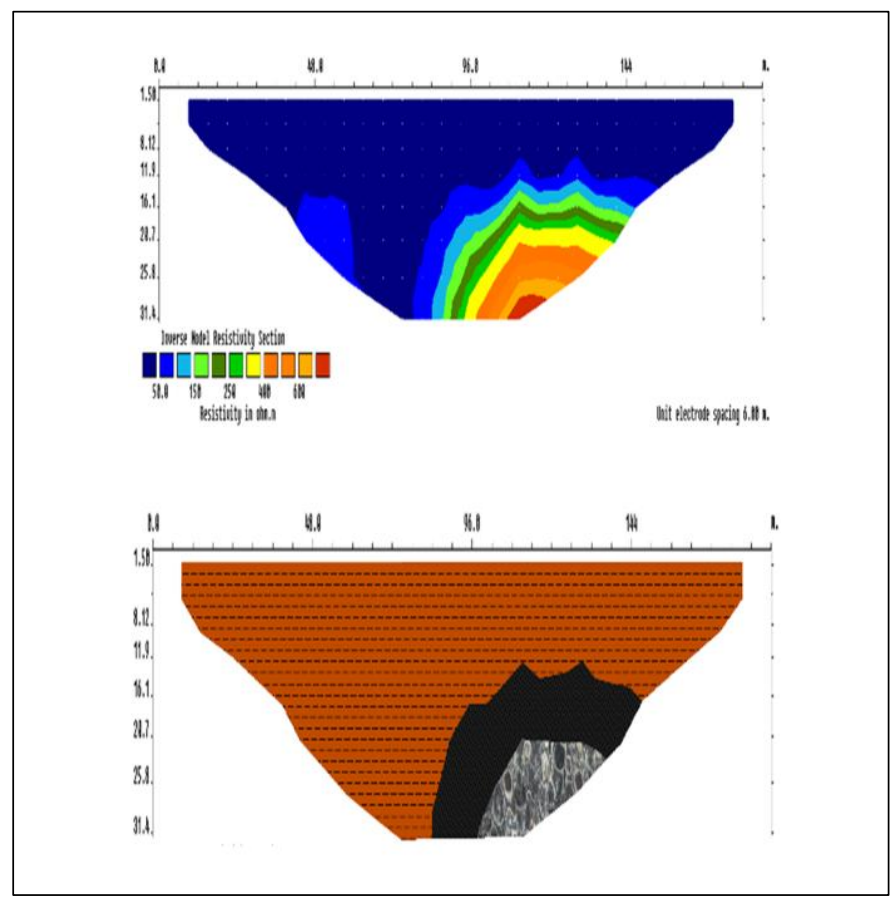

Gambar 5. Penampang Geologi Resistivitas L.1

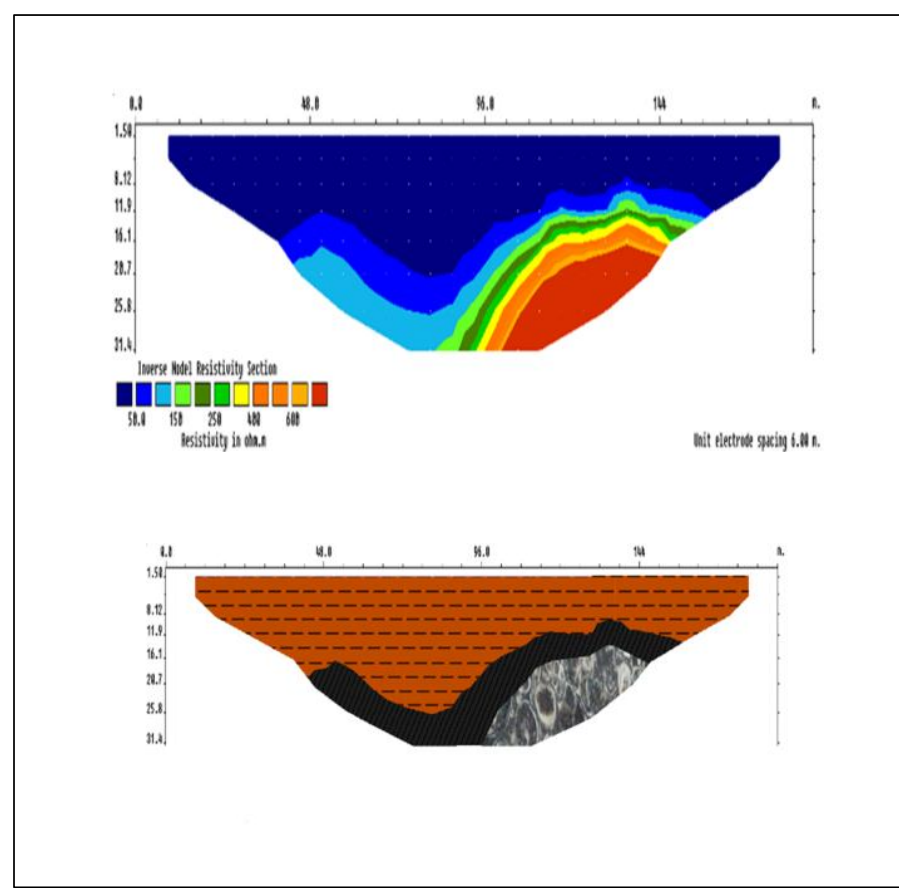

Gambar 6. Penampang Geologi Resistivitas L.2 


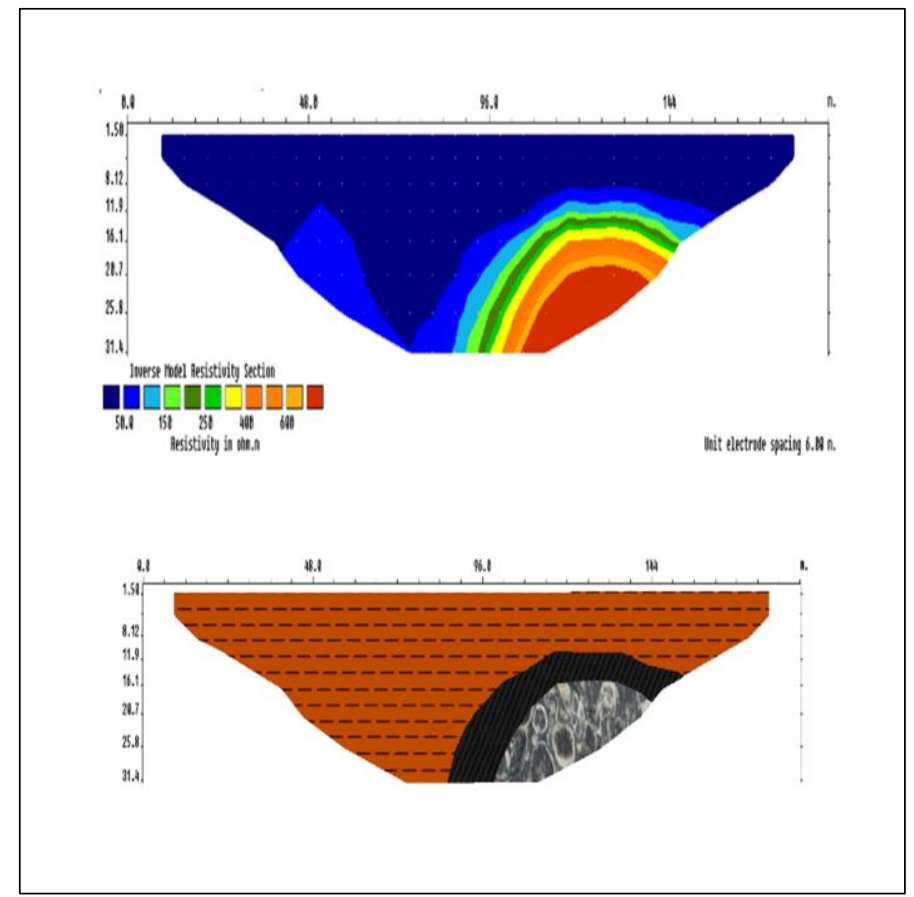

Gambar 7. Penampang Geologi Resistivitas L.3

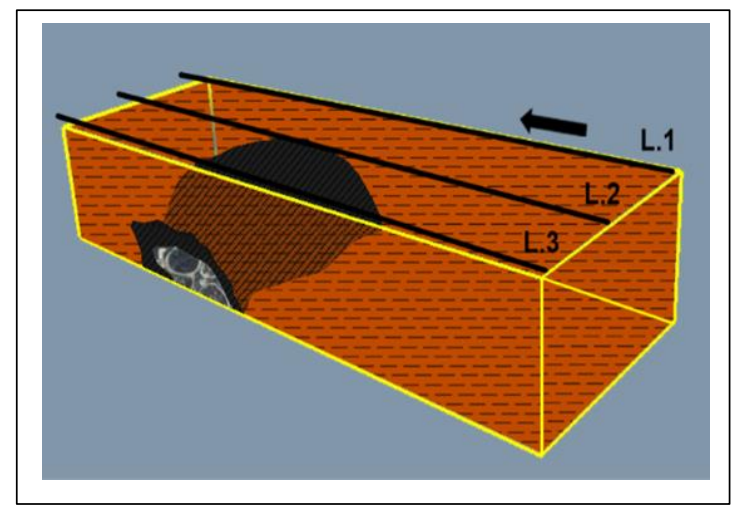

Gambar 8. Penampang Geologi Lokasi Penelitian 3D.

Untuk gambar penampang geologi lokasi penelitian 3D dapat dilihat pada Gambar 8. Ditinjau dari Gambar 9, hasil dari penelitian diperoleh penjelasan, bahwa terdapat beberapa litologi batuan yang ditemukan pada tiga lintasan (L.1,
L.2, dan L.3) pengukuran geolistrik di lokasi penelitian, antara lain lempung tufaan $(<100 \mathrm{~m})$ yang terdapat pada kedalaman 0 hingga 31 meter, batupasir tufan (100-600 m) yang dapat ditemukan dari kedalaman 11,1 hingga 16,9 meter, dan yang terakhir 
Agustina., Pazha., Wiratama., Chusni. - Identifikasi Litologi Batuan ...

adalah batugamping (> $600 \mathrm{~m}$ ) yang cukup besar dan dapat ditemukan dari dihasilkan dari pengerasan sisa-sisa kedalaman 17-20,7 meter di bawah tumbuhan dan moluska yang tersebar permukaan tanah lokasi penelitian. ke dalam bongkahan, ukurannya

\begin{tabular}{|ccc|}
\hline $\begin{array}{c}\text { Litologi } \\
\text { Batuan }\end{array}$ & $\begin{array}{c}\text { Indeks } \\
\text { Geologi }\end{array}$ & $\begin{array}{c}\text { Indeks } \\
\text { Tahanan Jenis }\end{array}$ \\
\hline Lempung tufan & & $\square \square$ \\
\hline Batupasir tufan & & $\square \square \square$ \\
\hline Batu gamping & $\square \square \square$ \\
\hline
\end{tabular}

Gambar 9. Penjelasan Litologi Lokasi Penelitian.

\section{KESIMPULAN DAN SARAN}

Dari pengukuran geolistrik yang telah dilakukan, ditemukan litologi lokasi batuan untuk tiga lintasan (L.1, L.2, dan L.3) yang tersusun dari lempung tufaan dengan tipe resistivitas/resistivitas di bawah 100 $\Omega \mathrm{m}$. Batupasir tufaan dengan nilai resistivias antara 100 sampai $600 \Omega \mathrm{m}$, dan batugamping dengan nilai resistivitas di atas $600 \Omega \mathrm{m}$.

\section{DAFTAR PUSTAKA}

Arifin, S. (2012). Identifikasi Struktur Bawah Permukaan Tanah dengan Metode VLF. Institut Sepuluh Nopember.

Bhattacharya, P. (2012). Direct current geoelectric sounding: Principles and interpretation.

Bowles, J. E., \& Hainim, J. K. (1984). Sifat-sifat fisis dan geoteknis tanah (mekanika tanah).

Google.inc. (2018). Google Map.

Hendrajaya, L., \& Arif, I. (1990). Geolistrik Tahanan Jenis. Monografi: Metoda Eksplorasi. ITB.

Khalil, M. H. (2006). Geoelectric resistivity sounding for delineating salt water intrusion in the Abu Zenima area, west Sinai, Egypt. Journal of Geophysics and Engineering, 3(3), 243.

Knödel, K., Krummel, H., \& Lange, G. (2013). Handbuch zur Erkundung des Untergrundes von Deponien und Altlasten: Band 3: Geophysik. SpringerVerlag. 
Agustina., Pazha., Wiratama., Chusni. - Identifikasi Litologi Batuan ...

Lashkaripour, G. R. (2003). An investigation of groundwater condition by geoelectrical resistivity method: A case study in Korin aquifer, southeast Iran. Journal of Spatial Hydrology, $3(2)$.

Loke, M. H. (1999). Electrical imaging surveys for environmental and engineering studies. A Practical Guide To, 2, 70 .

Mohammed, I. N., Aboh, H. O., \& Emenike, E. A. (2007). A regional geoelectric investigation for groundwater exploration in Minna area, north west Nigeria. Science World Journal, 2(4).

Reynolds, J. M. (2011). An introduction to applied and environmental geophysics. John Wiley \& Sons.

Silitonga, P. (1972). Peta Geologi Lembar Bandung. Direktorat Geologi.
Syamsuddin. (2007). Metode Geolistrik Tahanan Jenis 2D. ITB.

Viridi, S., \& Hilfan, K. (1995). Modul Semester Break Fisika Bumi. ITB.

Wahyono, C. S., Utama, W., \& Priyantari, N. (2013). Penentuan Bidang Gelincir Pada Daerah Rawan Longsor Dengan Menggunakan Metode Geolistrik 2-D Di Desa Lumbang Rejo, Prigen, Pasuruhan. Program Pasca Sarjana Fisika. Jurusan FMIPA ITS, Surabaya.

Wijaya, A. S. (2015). Aplikasi Metode Geolistrik Resistivitas Konfigurasi Wenner Untuk Menentukan Struktur Tanah di Halaman Belakang SCC ITS Surabaya. Jurnal Fisika Indonesia, 19(55). 